"We're Holding our Ground": Body Politics, Verbal/Non-Verbal Performance, and Dissent Aesthetics in Rafeef Ziadah's Performance Poetry

\title{
Amany Elnahhas
}

Assistant Professor, Faculty of Arts, Helwan University, Egypt.

\begin{abstract}
Rafeef Ziadah is a Palestinian performance poet and human rights activist who uses the power of the spoken word interfused with stage performance in order to mainstream Palestinians' experiences of occupation, diaspora, and dispossession as much as the daily struggle for survival, steadfastness, and resistance into American and human pop culture. Performance Poetry, as such, has become a platform for social and political dissent where the poet/performer begins her performance with a Palestinian story at the same time that she instructs her audience to "click, clap, or smile" in order to engage with the Palestinian narrative. The paper weaves together performance studies and body politics in order to examine the interplay between the spoken word and storytelling, on the one hand, as well as facial expressions, voice, movements, and audience engagement as integral to the performed art, on the other. The paper also examines the negotiation between art and politics as well as the aesthetic value of performance poetry and its socio-political implications on the other through different approaches to Aesthetics theory with particular reference to R.G. Collingwood and Marshall McLuhan. Moreover, it explores the social, political, and lived aspects of aesthetics that the performance poet attempts to illuminate by drawing attention to the networks of solidarity within and without the Palestinian community.
\end{abstract}


Rafeef Ziadah is a Palestinian performance poet and human rights activist who uses the power of the spoken word interfused with stage performance in order to mainstream Palestinians' experiences of mass slaughters, occupation, diaspora, and dispossession as much as the daily struggle for survival, steadfastness, and resistance into American and human pop culture. Performance Poetry, as such, has become a platform for social and political dissent where spoken word artists, in general, and Ziadah in particular, have engaged with the audience/recipients to help them understand, feel, and interact with the poet, not only through the words uttered, but also through the way the spoken words are communicated. The paper examines the negotiation between art and politics as well as the aesthetic value of performance poetry and its socio-political implications through different approaches to Aesthetics theory with particular reference to R.G. Collingwood's theory of expression in addition to other interdisciplinary perspectives on gestural communication conjoined with the spoken word. The first part of the paper weaves together performance poetry and body politics by drawing on the emotional and visual significance of hand gestures and dress, respectively, as more than simple or decorative choreographed cues, but rather key elements of performance poetry. The second part elaborates further on the interaction between the personal and political aspects of dissent aesthetics through the distinctive verbal tools of bantering, elevator pitching, and codeswitching in order to provide a comprehensive thematic analysis that draws attention to the interrelationship between auditory performance, the meaning of the body, and dissent aesthetics.

The oral basis of pre- and early Islamic Arabic poetry was a central common feature that was shared with Ancient Egyptians whose literary papyri and hieroglyphics show a long history of orality that was practiced both privately as well as publicly through literary elite readings (Jay 12). Michael Zwettler adds that oral performativity, rather than recitation or verbal transmission, through improvisation marks the beginning of classical Arabic literature. In other words, the act of literary composition through verbal expression was an act of creativity that was later rendered into textualization or writing, not vice versa (Zwettler 4). Other writers state that pre-Islamic poetry was an audio-vocal form of expression that began in song format and expressed the individual and collective forces at play at the time (Adonis and Cobham). In Medieval Arabic times, performance poetry was presented in literary and artistic salons that surfaced in Iraq in the $9^{\text {th }}$ century and prospered in the $10^{\text {th }}$ century before it expanded to North Africa, Andalusian Spain, and the west. While Iraqi literary salons served as a flourishing space for cultural and political discourse as well as educational and entertaining purposes ("Explore Iraq"), their Egyptian counterparts in Cairo were not much different. Egyptian intellectuals used the sanctity of their homes to verbally articulate their artistic expressions as well as discuss highly controversial and heated topics during times of conflict, particularly the British occupation of Egypt. This oral tradition pursued further in the literary works of devout poets who perceived of poetry as a vehicle of both individual and collective expression. Their oral form of poetry captured in the social and political protest against long-existing struggles against political tyranny, colonialism, imperialism, classism, and sexism among other hegemonic and asymmetric power relations. Salah Jaheen, Abdel Rahman Elabnoudy, and Ahmad Fouad Negm are some of the most eminent writers who took poetry into a whole new level. Their colloquial poetry broke up the blunt division between low and high art, orality and literacy, or mass public and elites turning their poetry in both its written and oral form (whether recited or sung by popular singers at the time) into newer horizons. Those poets were the voices of dissent and the unyielding mouthpieces of the masses, the poor, and the oppressed. The most prominent voice among them was Ahmad foad Negm who spent a good part of his life in prison standing up for his oppositional and revolutionary beliefs. His partnership with the well-known composer Elsheikh Eman manifested the way poetry has turned into songs and politically 
fraught chants in protests, demonstrations and other forms of political opposition that spoke against tyrannical regimes and energized the masses.

Recently, performance poetry has manifested itself in reading clubs, public libraries, shows and artistic performances at Elsawy Culture Wheel ${ }^{1}$ or the most popular reality talent show "Prince of Poets" or "Amir Elshu3ara2." Though Prince of Poets followed in the footsteps of western reality, competition and game shows in Europe and the United States ${ }^{2}$, "Prince of Poets" 3 managed to secure an overwhelming popularity in the Arab World through its focus on reinvigorating classical Arabic as a means of poetic expression as well as bolstering people's interest in a long-dwindling cultural and historical heritage.

In the West, Performance poetry in its modern form has been defined as a genre of rapidly growing oral poetic expression that began in the sixties and seventies (Grabner 3). Though it is one of the most modern artistic forms of aesthetic human expression, performance poetry can be traced back to Homer's "The Iliad" and "The Odyssey," Shakespeare's writings, Elizabethan verse performed in theaters, in the same way that it can be traced to a whole history of oral tradition (Attridge 4,340). Performance poetry has taken a variety of artistic voiced formats. These voiced formats refer to different varieties of colorful, lively, high-energy expression of art that include punk poetry, protest poetry, jazz poetry, political poetry, punch poetry, stand up poetry, love poetry, open mic poetry, and angry poetry. Performance poetry attempts to, above all, engage with live audience in poetry festivals, cafes, literary clubs, cultural centers, bars and libraries. In order to ensure a diverse and international audience, performance poetry has reached out to televised audience through different television networks, as well as to online audience through independent media outlets including YouTube, or PoetrySoup ${ }^{4}$. As an oral form of artistic expression, performance poetry is written with the specific intention of having it performed out loud in public. This idea represents the key difference between performance poetry and the printed format of both traditional and contemporary written poetry that focuses solely on the interaction between imagery, symbolism, rhyme and meter to create the emotional intensity of the poem. The audience, therefore, is a key factor in the spoken word performance, and the ability to influence, change, touch, challenge, persuade, move, and deeply engage this audience is a major priority in any performance poetry. Moreover, performance poetry explores a range of highly sensitive and controversial issues that have been rarely addressed in the traditional form of poetry. These issues include sexual violence, drug addiction, domestic violence, police brutality, male engagement, anxiety, depression, and OCD as much as they address economic and political issues like capitalism, Marxism, the American dream, poverty, and American foreign policies.

Ziadah belongs to a long gallery of well-acclaimed artists and performance poets of Arab descent including Farah Chamma, Maysoon Zayid, Hala Alan, Sabrina Mahfouz, Suheir Hammad, Dana Dajani, Harlan Alan, among others, who have reshaped the genre of poetry both aesthetically and thematically. Performance poets do not simply attempt to recover and accentuate a highly revered cultural and historical heritage, but also strive to bring to light their deeply ingrained contemporary concerns. Through their spoken word performance, they highlight critical issues of displacement, denial of nationhood, identity conflict, as well as joint historically based Arab dilemmas especially as they relate to the Arab-Israeli conflict. As such, their poetic performances underscore both their literary and artistic talents, but more importantly their people's struggles to resist constant and tenacious attempts at cultural and historical annihilation both as Arabs and as an ethnic minority in the West. In other words, performance poets writing in the west do not just integrate Western Arab voices into a highly closed textual corpus of artistic expression, but they also attempt to engage the Western audience into their cultural and political realities. 


\section{Body politics, nonverbal communication and Dissent Aesthetics}

Despite the previous reassuring value of performance poetry, there are various and complex concerns at hand here. One of the main concerns that need to be addressed here involves the confluence of non-verbal elements of performance poetry and dissent aesthetics. In order to clarify this point, the paper highlights the gestural and visual aesthetics or rather the bodily manifestations of non-verbal communication of Ziadah's performance poetry as they interact with dissent aesthetics. In other words, the paper examines the interplay between body politics, emotional and visual engagement, on the one hand, and audience engagement as integral to the performed art, on the other.

The aesthetic movement (also known as aestheticism) is one of the most influential artistic and intellectual European movements of the late $19^{\text {th }}$ century that held a principle axiom of "art for art's sake" emancipating art from any moral or empirical considerations (Felix-Jager 30). It is primarily focused on a deliberate and passionate emphasis on beauty, sensuality, pleasure and taste as foundational values in both art and life. Though this sensual-based approach applied mainly to fine and applied arts, it extended to include music, dance, decorative arts, fashion, interior design, and literature. Pioneering figures of the aesthetic movement include William Morris and Dante Gabriel Rossetti, Oscar Wilde, Théophile Gautier, R. G. Collingwood, and Theodor W. Adorno.

Some of the most basic arguments in aesthetics include the definition, nature, function, and object of art that were manifested in heated and unwavering debates between the expression theory of art, aesthetic cognitivism, or conceptual art on the one hand, and aesthetic autonomy or aesthetic disinterestedness, on the other hand. While the former approach toward art fosters a robust belief in the educational value of art, the latter perceives art to be an autonomous part of culture as it serves to fulfill man's hedonistic desires regardless of its educational significance (Guter 40; Smith 7). Moreover, the conceptual art approach that began in the second half of the twentieth century carries this point further as it emphasizes the idea that the real core of art lies in the ideas, beliefs or concepts that the artist attempts to communicate rather than the artwork's formal or material content (Mooney 2). This idea is further accentuated through Collingwood's expression theory of art which, like theories of representation, asserts the communicative significance of art.

Robin George Collingwood is a renowned English philosopher, archaeologist, and historian and one of the major contributors to Aesthetic theory who challenges the idea of art as craft that is deeply held by the technical theory of art. In his highly informative and controversial book The Principles of Art (1938), Collingwood differentiates between 'craft' and what he calls 'art proper' which identifies the true essence of a work of art. Collingwood asserts that art proper is an 'internal' or 'mental' thing, something (as we commonly say) 'existing in [the artist's] head' and there only: something of the kind which we commonly call an experience" (37). He closely connects art proper to what he terms "magical art' while disqualifying amusement as the only criteria to judge a literary work as art (91).

Collingwood believes that 'magical art' is that which "evokes of set purpose some emotions rather than others in order to discharge them into the affairs of practical life" (69). Though this basic principle in the expression theory of art defies the traditional definition of poetry, it could easily apply to performance poetry that has much in common with other forms of art. Like the ceremonial dinner party, performance poetry intends to "create or renew a bond, not of understanding or interest or policy, but simply of emotion ..." (Collingwood 75). This emotional bond lies between the poet and his/her audience on the one hand, and the audience 
and the cause/concepts/memeories/ideas/feelings/people that the performance poet wants to connect the audience to, on the other hand

If we apply Collingwood's notion of 'art proper' to Ziadah's poetry, the latter would render a work of art that necessarily 'expresses' rather than 'arouses' certain emotions. While defying the identification of art with craft, Collingwood asserts that the difference between expressing emotions and arousing them lies in whether the artist have prior knowledge of the feelings he wants to stimulate in the recipient. Whereas expressing emotions indicates shared emotions that the poet/artist shares with his readers/audience through both language and consciousness, arousing emotions indicates the poet/artist's stimulation of emotions without necessarily identifying with them. In this sense, Collingwood believes, art proper lies mainly in 'expressing' rather than 'arousing' art (109). While the latter indicates the production of a pre-conceived, pre-determined, and highly thought out 'product' which degrades the function of art proper into that of craft, the former implies the 'creation' of an internal intellectual experience through which the poet/artist can express his/her emotions, at the same time that he attempts to make the recipient "understand how [artists/poets] feel" (Collingwood 110).

Feelings in this sense mark the beginning of the mental experience of art; they are the launching pad for whatever thoughts are to follow. This view is supported by John Holloway who points that thoughts are derived from feelings especially anger, conflict, or rejection "not from the pose of reason, not from the reasoned-sittingback-and-reflecting-on-the-mysteries-ofexistence ....We start from negation, from dissonance. The dissonance can take many shapes. An inarticulate mumble of discontent, tears of frustration, a scream of rage, a confident roar. An unease, a confusion, a longing, a critical vibration" (1). Body language represents one of the basic tools for self-expression that is natural and involuntary, yet communicative of what the speaker feels and how s/he wants his/her audience to feel. Performance poetry lies at the intersection between the non-textual elements of the spoken word, including movements, gestures, on the one hand, and the textual elements that stress the thematic and symbolic aspects of the text on the other.

These ideas are explored further by David McNeil and Adam Kendon who assert the co-development of speech and gestures. Giacomo Rizzolatti and Michael Arbib, on the other hand, argue that gestures precede language in the evolutionary process. Rizzolatti and Arbib's findings are crucial here because they assert not just the synchronous efficacy and presence of language and gestures, the spoken word and gesticulations, or vocalization and non-verbal expression, but also the idea of communicative gestures as the foundational basis of language. In an attempt to explain the evolution of language, Rizzolattia and Arbib found out that the human mirror neuron system, which is composed of smart cells of the neural network system, is stimulated by simply observing other gestures. The emphasis on the gestural basis of language lies in the fact that the performance of any communicative gesture/ action together with the simultaneous observation of this very gesture/ action activates the same brain activity stimulated by the actual enactment of the action. When applied to performance poetry, this means that witnessing the arm and hands movements, postures of the poet/performer enable the audience not only to share the 'expressed' emotions of the poet/performer, but also to understand his/her intention. In other words, gestures, including hand and arm movements are not incidental, but essential components of the performance; they are key elements of action decrypting, social interaction, and empathy (Rizzolatti and Craighero 2004). As such, the visual stimulation that occurs while observing the performance of co-speech gestures discharge mirror neurons that facilitate the interpretation of the performed action (in this case gestures).

This indicates that gestures express more than the outer appearance of reality. This expression theory of art has its origins in Aristotle's account of mimesis. According to 
Aristotle, mimesis (also refers to imitation or the representative aspect of art) is a creative and productive aesthetic action as he states that "imitation is given us by nature and men are endowed with these gifts, gradually develop them and finally create the art of poetry" (qtd. in Richter 43). This act, accordingly, is one of "creation" rather than "repetition," one that aims at not only "depicting and illuminating a world that is (partly) accessible and knowable outside art, and by whose norms art can therefore, within limits, be tested and judged," but also constructing "an independent artistic heterocosm, a world of its own" (Halliwell 5). In other words, in the act of 'representing' reality, the artwork transcends external reality into creating one of its own. Theodor W. Adorno elaborates this idea further by claiming that despite the connection between art and external reality, "artworks nevertheless have a life sui generis. This life is not just their external fate .... Artworks are alive in that they speak in a fashion that is denied to natural objects and the subjects who make them" (4-5). This means that the meansto-an-end technique, which applies to crafts, cannot be extended to art because the artist, unlike a craftsperson, does not know in advance the exact emotions s/he will stimulate. Expressing an emotion, therefore, is "a directed process: an effort, that is, directed upon a certain end; but the end is not something foreseen and preconceived...." (Collingwood 111).

The unpredictable and unconscious nature of these feelings is transposed into consciousness only in the act of expression. Collingwood argues that despite the artist's awareness of the presence of 'certain' emotions that need to be expressed, s/he remains unconscious of the specific essence of these feelings which is a state that Collingwood describes as one of "perturbation or excitement" (109). It is only through "expressing' these emotions that the artist can attain a 'conscious' state of 'lightened' emotions. These lightened emotions, however, do not lead to the purging or elimination of feelings as in case of 'catharsis', but to a more conscious and enlightened state whereby we can clearly identify and 'recognize' our feelings instead of the mere condition of 'unidentified perturbation' (Collingwood 111). In a similar vein, in performance poetry it is only in expressing the poet's emotions through movement, gestures, and other material aesthetic elements that the final poem is created and the feelings identified.

This presumes that whether perceived as unintentional or unplanned as a result of a spontaneous response to certain emotions experienced during the actual performance, or as premeditated movements that are rehearsal induced, that is, generated during the rehearsal performance of the performed poem itself, gestures remain spontaneous acts of self-expression that occur post the writing process. In other words, though performance poetry is written particularly to be read or performed on stage before an audience, it is only during the rehearsal, then later during the actual performance that gestures come up in order to express how the performer poet feels and to facilitate the communication of these feelings to the audience. Ether Thelen and Linda Smith reflect on this point as they observe that "dynamic systems [as in performance poetry] seek preferred behavioral modes as a function of the interactions of their internal components and their sensitivity to external circumstances" (qtd. in Lutterbie 39). In other words, it is only in the interaction between inner feelings and the external world that certain behavioral modes, movements, or gestures are produced. Gestures generated accordingly enable the reliving of the experiences narrated and the feelings expressed. They reinforce the body as a textual experience in the same way that the text reinscribes the body as a physical experience.

Therefore, the lightening of emotions attained through gestures is an act of 'discharging' feelings, of marking the poet's feelings and movements into the hearts and minds of the audience. The way Rafeef Ziadah holds one hand over her heart in most of her poems is a cross-cultural gesture that indicates honesty and geniunness in what the poet wants to 
communicate to the audience as well as a strong and unyielding desire to be believed, acknowledged, and admitted into a whole human history from which they have been denied. But more importantly, in the act of expressing her emotions and those of her people, Ziadah is adamant upon delving into the very specificities of the Palestinian experience as a distinct and unrivaled experience. While steering away from "labelling his emotions", the poet, in Collingwood's vision, "takes enormous pains to individualize [emotions] by expressing them in terms which reveal their difference from any other emotion of the same sort (113). Likewise, Leo Tolstoy states that it is the expression of feeling as 'experienced' that identifies a devout artist. "The more individual [one's feeling] is," he adds, "the more the artist has drawn it from the depths of his nature - the more sympathetic and sincere it will be" (qtd. in Diffey 25). For example, on introducing her poem "The Palestine I know" Ziadah holds one hand close to her heart when she refers to the Palestine she "grew up with." Later, she starts patting on her heart further on mentioning "the Palestine" as if to stress a genuine presence of her 'self' and her people against all form of denial, annihilation, and persecution. Ziadah continues to place her hand close to her heart as she adds what Palestine means for her: "the Palestine that taught me everything I know about Palestine/ and it mainly came through women and I think it's women who usually hold the story of their nation and I think that's why it's very important in the arts to also always acknowledge women ..." (“The Palestine I know" 00:01-00-18).

Michal Parzuchowski, Aleksandra Szymkow, Wieslaw Baryla, Bogdan Wojciszke argue that the value of the hand-over-heart gesture lies not just in the feelings of trust and honesty they generate in the speaker but also in how the action is perceived by the recipient/audience. In other words, the bodily-instigated expression of the hand-over-heart gesture stimulates a semantic interpretation of truth and sincerity not only in the poet/ performer but also in the recipient/audience (238). This semantic interpretation is both emotional as well as behavioral in the sense that the poet/performer of the gesture, just like the recipient/audience, are more likely to behave in a more honest and moral way when performing or witnessing honest-related gestures (in this case the hand-over-heart gesture) (Parzuchowski et al. 241).

To explain her rejection of performing the role of an Israeli soldier, even during a direct action in her university, Ziadah uses the palms down gesture (also called pronation ${ }^{5}$ ), while introducing "Shades of Anger", as an extremely significant example of her defiant stance. The angled pronated gesture that she employs while saying that she "will only be a Palestinian. [She] refuse[s] to be a settler or soldier" $(0: 21-0: 25)$, as McNeill claims "denies, negates, interrupts, or stops something -metaphorized as an incoming force, a beam, with the palm as a barrier" (102). The same is communicated through the hand in pronation gesture that Ziadah uses as she says "we are returning to Falsteen" (Ziadah, "Shades of Anger" 1:51 - 1:53) while using the chopping gesture emphatically as if trying to disrupt any other alternatives. On other occasions, she uses the palms down gesture while outstretching her arm at an angled position and screaming "Let Ghazzeh speak, Let Rafah speak, Let Janeen speak, Let Jerusalem speak, Let Chateela speak, Let Dair Yasseen speak..." in order to proclaim an assertive, selfconfident, and non-negotiating position ("If My Words" 4:45 - 4:52). Other dominant gestures that clearly express the performing poet's disapproval, dismissal, negation, and outright rejection of the current state of affairs include hand wagging, finger wagging and head wagging which Ziadah employs repetitively and emphatically in her poems. These gestures serve to enforce the poet's feelings, communicate her message, and ground her stor(ies) into the mind and soul of her audience

Outstretched hands and arms are also some of the common gestures that Ziadah repeats throughout her performance poems. Both gestures show the scale and enormity of the event or 
action referred to through the performing poet's words. For example, extending both arms during some of her performances allows Ziadah to occupy an actual large physical space which, accordingly, reflects the overpowering force of her feelings. On other occasions, Ziadah extends one arm to the side while holding the microphone with the other arm as she does in "If My Words" as she regretfully explains how Palestinians are remembered "only when there is a mass slaughter that is being televised going on" $(0: 15-0: 20)$. The double gesture of the horizontally extended arm along with the microphone-holding hand are doubly symbolic of Ziadah's consciousness of the heinousness of their underreported massacring at the same time that the microphone-holding hand signifies her determination to speak up against the intentional cultural and political invisibility of Palestinians except as "televised" massacres.

Closing her eyes, extending her hands forward toward the audience, flashing a transient smile before wagging her head are some of the non-verbal sequence of movements that Ziadah demonstrates in "We teach life, sir" in order to convey a series of complicated yet complementary feelings. While the closed eyes gesture expresses the performing poet's attempt to reconnect with her 'self', with an ongoing inner pain, the hand reach indicates a serious attempt to connect with the audience and to engage them with the dilemma of her people as she says "I give them UN resolutions". On the other hand, the transient smile (as she refers to UN resolutions) before wagging her head with "and we condemn and we deplore and we reject" (Ziadah, "We teach life, sir" 3:06-3:11) communicates not only her utter feelings of disappointment and frustration at these organizations but also her total dismissal of the constant unswerving failure of the UN to enforce any serious binding resolutions.

Compartmentalization is another communication gesture that Ziadah employs throughout her poems. For example, she uses the visual right to left hand shifting with open palms facing downward then forward as she says: "These are not two equal sides: occupier and occupied" in order to create a so-called "us vs them mental and emotional difference" in the minds and hearts of her audience (Ziadah, "We teach life, sir" 3:12 - 3:16). This particular gesture serves to categorize occupier vs occupied, or rather to stress the unsurmountable difference between them, a difference that has been widely ignored by Western political discourse.

Gestures, as such, serve to enhance, illuminate, and further communicate a cognitive value that go beyond the perceptual medium. Recent studies have shown that beyond the perceptual process achieved through the visual or sensory experiences, more complicated cognitive processes linked to memory and classification are also attained (Michel). In other words, the visual reception of gestures improve both one's sensory perception and cognitive faculties which, accordingly, assists in the reflection, categorization, and overall emotional and mental interpretation of the performed poem.

But the most expressive gestures used by Ziadah are those that pertain to rap musical performances. Rap music is a mainstream genre of hip-hop that came to dominate the music business in the 70s in New York (Broome and Munson ix). As part of the hip-hop movement, rap represented a counterculture that was instrumental in bringing the socio-political matters of black youth to the fore. It provided a watershed that propelled innovation, creativity and rebelliousness, at the same time that it presented a subversive form of cultural and aesthetic expression (Broome and Munson 17). Conscious rap (also known as nation-conscious rap), in particular, was a sub-genre of hip hop that promoted social and political reforms and advocated for communal self-definition, peace, freedom, justice, and equality, while also known for endorsing violence and misogyny. Like rap performances as well, performance poetry uses the very animated form of expression to communicate similar concerns. In the same way that a hand or finger pointing rap gesture communicates a sense of power or 'domination' over an 
urban setting (Galhano-Rogues et al. 104), Ziadah's performances use these gestures to communicate a strong urge to have control over their lives. It is a performance of resistance that symbolizes the Palestinians' inclusion into the Western modern rap setting as well as the Palestinian longing for territorial and cultural control over their homeland. While rap employs forward finger pointing, territorial/pointing and metaphoric gestures of body altercations to indicate a strong sense of control manifested in social agency, and resistance against dominant institutions of power (Galhano-Rogues et al., 105), Ziadah's gestures communicate similar meanings through using almost the same gestures. In "Shades of Anger," Ziadah uses finger pointing while holding her thumb up in a rap gesture shifting between herself and the 'other' as she says:

\author{
'You' tell me \\ I send $m y$ children out to die \\ But those are 'your' 'copters, your F16s in our skys
}

As such, the repetition of the words 'you', 'your', 'my', and our' along with the accompanying gestures have served to create a sense of confidence, power, and empowerment.

The visual display of emotion in performance poetry, however, goes beyond gestures. The way the poet dresses in a certain garb rather than another is an integral part of the message communicated and the feelings expressed. In her performance shows, Ziadah dresses in the 'thobe,' the traditional Palestinian costume. Traditionally, the thobe is an embroidered long handmade loose heavy attire with colorful designs and stylized motifs originally worn by Palestinian peasants or village women. Historically and politically, the traditional local dress has been an iconic symbol of steadfastness, power, and resistance. Beyond the aesthetically pleasing value of the dress, the way Ziadah shows up on stage serves to assert more than the dress' artistic value. Besides employing the dress to stress the strength of their presence, Ziadah adds another dimension to the visual impact of the dress that juxtaposes its traditionalism with a touch of modernity. This is manifested in Ziadah's transformation of the Palestinian garb into a short-sleeved shirt that carries the same distinct red designs into a modern setting. As such, the dress has become another act of 'dissent' that defies the constant and ruthless attempts of what Sonja Mejcher-Atassi calls "museumization." Museumization was originally devised to secure a sense of national identity and cultural pride, but it led to further cultural loss as displayed objects "were now being 'fossilized' and displayed in a static manner distancing them from their origins" and stripping them from the "complex meanings [they] had carried for generations within the rural context of the Palestinian society" (86). Instead, Ziadah's appearance on stage serves a different purpose: visual assertiveness. Visual assertiveness is a means through which Ziadah has managed to stress a presence on stage that moves the traditional dress beyond the confines of the museum or the annals of dress history into a live presence. As such, the traditional Palestinian dress has continued to carry its story and to celebrate its people's distinctiveness, while simultaneously acknowledging newer horizons and allowing the audience to see Palestinians through a different and fresh modern perspective.

\title{
A thematic Exploration of Auditory Display, the meaning of the body, and Dissent Aesthetics.
}

Despite the intensity of the feelings expressed through the sensory aspects of the poem, Ziadah's performance poetry carries an equally significant, intellectual politically and historically stimulating discourse that derives from her experience as both a Palestinian and an activist. Though a Palestinian, Ziadah has never actually lived in Palestine; she is a third generation refugee who has lived through her people's displacement, the 1982 siege of Beirut where she was born, and a persistent state of displacement and statelessness that followed. 
Furthermore, Ziadah is a politically vocal activist who has worked with asylum seekers and refugees in different countries as a member of Boycotts, Divestment and Sanctions (BDS) movement, a participant in the panel of John McDonnell's "Economics for the Many", and a spokesperson for the Palestinian civil society organizations, among other activism-based posts. Consequently, she has been an ardent progressive promotor of justice, equality and freedom, not only for Palestinians, but for all. As such, Ziadah believes that poetry could not and should not be sealed off from politics. In her interview with Hazem Jamjoum, she notes:

It's difficult to me to separate out the politics [from poetry] because it's ingrained in my entire history - being born into a war and invasion in Lebanon, growing up undocumented as a Palestinian refugee, seeing the first intifada, the second intifada, the current popular uprising that's going on on the ground - it speaks to me."

(Barrows-Friedman)

This means that Ziadah writes and speaks about issues with which she is not only concerned about and engaged with, but also "a witness" to. Kia Lindroos and Frank Möller assert that a positive "visual and/or bodily engagement" with the experiences "witnessed' is a prerequisite for the artistic experience of what they call "the politicalness of artistic witnessing" (33-34) which is an illustration of engaging with real life.

Therefore, Like patriotic poems, historic plays and pictures, or ancient monuments, the 'magic', to use Collingwood's word, of performance poetry lies not just in expressing momentary emotions, but in channeling these emotions "into the activities of everyday life and modifying those activities in the interest of the social or political unit concerned" (Collingwood 73). In a similar vein to Collingwood who asserts the inclusion of poetry into everyday life, David Constantine draws attention to the power of poetry being "common, commonplace, it thrives in and serves our common lives, but does so by virtue of its slant relationship to them. Poetry lives in that dynamic tension; fails and dies with it" (3). Hence, in Collingwood's terms also (just like dancing, religious ceremonies, or songs), performance poetry is both representative and symbolic in the sense that it is meant to bring people together, not only within the limited public space of the theatre or the hall where the performance poetry takes place, but more importantly into the wider mental and intellectual space of the context of the performed poem or rather into the preconceived connection with the human Palestinian dilemma.

Kicking off her performance poetry with 'an elevator pitch' (also called 'elevator statement' or 'elevator speech') is a good example of this act of channeling the audience's emotions into the daily life struggles of Palestinians. Ziadah introduces one of her most remarkable performance poems "We teach life, sir" with an elevator pitch in which she gives a brief account of the terrible circumstances during which she wrote her poem (the bombing of Gaza) and her position at the time as the media spokesperson for the coalition of Palestinian civil society organizations. More importantly, she also sheds light on the incident that prompted her to write the poem: when a journalist asked her "don't you think it would all be fine if you just stopped teaching your children to hate?" (Ziadah, "We Teach life, sir" 0:37 - 0:43). This elevator pitch manages to capture the audience's attention, assert the poet's authority, and therefore, stress the credibility of what she was about to speak about, respectively. But above all, Ziadah's creative elevator pitch smoothly sneaks the audience into the world of degradation and provocation that Palestinians have been exposed to in order to defend who they are and what they stand for.

Part of the auditory aesthetics of Ziadah's perfromance poetry includes language alternation or Code switching through which Ziadah maintains further a strong stance of dissent through language. Code switching describes the process whereby the speaker switches between 
more than one language. Ziadah consistently uses one type of code switching which is tag coding (also called tag switching or extra-sentential) where she introduces one word insertions, particularly as she pronounces certain Palestinian cities. For example, she insists on pronouncing Gaza in a Palestinian Arabic accent. She steers away from the English 'Gaza' and uses instead 'Ghazzeh.' The same is true as she uses 'Yaffa' rather than 'Jaffa', '7aifa' rather than 'Haifa' ("Shades of Anger" 1:15 -1:18) and, 'Falasteen' rather than 'Palestine'("Shades of Anger" 1:53) which creates a sense of comfort for her and introduces the audience to an alternative way of not just word pronunciation but also word presence. This is clearly supported in the opening lines of "Shades of anger" which manifest an inter-sentential code switching ${ }^{6}$ as Ziadah begins her poem with the Arabic sentence " اسحو الي أن أتكلم بلساني العربي قبل أن يحتلو الغتي "أيضا "before she switches into English: "Allow me to speak my Arab tongue/before they occupy my language as well/Allow me to speak my mother tongue/before they colonise her memory as well" (Ziadah 0: 39 - 0:51). Alternating between English and Arabic is an act of "selfpreservation and identity construction" which generates what Carmen Lee calls an "impression management" (55). Lee maintains that through impression management, the 'actor' in a sociolinguistic -face-to-face contact displays a variety of 'identities' that manifest the dialectic between "who we are ... who we want to be to others, and how others see us or expect us to be" (55). Language alternation in this sense expresses a multiplicity of identities and a wide diversity of experiences that are deeply ingrained in positive feelings of nostalgia, selfconfidence and power.

Bantering, as a spontaneous and playful conversation that Ziadah employs to begin her performances, is another significant part of the performative element of dissent that is directly intended to force the audience's attention into the genuineness of the Palestinian experience. Exchanging witty banter with her audience becomes an integral part of her poetic performance. It is an act that serves to not just elicit laughter, but also to build rapport with her audience, enhance the audience's awareness of the contextual background of her poem at times, or add a sense of psychological intensity at others. For example, at the beginning of "Passport," Ziadah begins her performance bantering by the fact that prior to the attainment of Canadian citizenship, new citizens swear an oath of allegiance to the Queen and her "heirs" which, as Ziadah points out, is widely pronounced by Arabs as 'hairs' (0:23-0:37). Ziadah employs this witty banter to engage her audience with the illegal status of Palestinians both inside and outside. At the oath of allegiance ceremony, the aesthetics of 'visibility' vs 'invisibility' play a fundamental role in understanding the dispersal of Palestinians. Between their 'invisibility' at the oath of allegiance ceremony, the only place where they are supposed to be acknowledged as people and as human beings, and their humiliating 'visibility' at checkpoints and airport searches lies a whole story of suffering, humiliation, and 'illegality.' Though Palestinians at allegiance ceremonies are not subject to invasive inspection or questioning the same way they are constantly exposed to while going through checkpoints, or regular airport security searches where their faces are examined, their bodies scrutinized, and their humanity degraded, what happens at allegiance ceremonies is equally as disturbing. At oath ceremonies, the strong sense of negative visibility Palestinians have been experiencing has been replaced by an equally humiliating sense of 'invisibility' that asserts that despite the absence of strip-searches, questioning and strictly inhumane airport protocols, "nothing changed."

These fluctuation between 'visibility' and invisibility' are closely tied in with Ziadah's constructions of body images. Where their bodies are constant markers of their diverse and striking experiences of occupation, exile, displacement, diaspora, and overall social and political exclusion from a normal and dignified life (where they are worldly recognized as numbers and statistics of refugees, casualties, suicide bombers, martyrs or potential martyrs), the body becomes the major transmitter of their realities. 
This is clearly manifested in the interrelationship between the physical body and the political body. The political body, in Ziadah's performance poetry, is materialized on and through the physical body. Consequently, the Palestinian physical body is the site where power is exercised, manipulated, and abused. Between the 'visibility' through which they are perceived as security threats or potential suicide bombers, and the 'invisibility' that denies the uniqueness of their overall history and experience at official oath ceremonies, Palestinian bodies have continued to be politicized through either 'violence' or 'denial.' Corporal violence is manifested during the routine unlawful and discriminatory law enforcement policies that are constantly perpetuated against Palestinians. These policies begin with ethnic/racial profiling, disguised as mundane security checks, where they have to go "to the back of the line" or "into a small room, that small room, in the back of airports that you never see" (Ziadah, "Passport" 2:11-2:16), and they end up with Palestinian bodies getting dissected, mishandled, and degraded by being strip-searched or intentionally targeted for temporary detention or incarceration. The violence of denial, on the other hand, is practiced against Palestinians in Western citizenship ceremonies. During these ceremonies, the bodies are subject to another form of annihilation.

But [the immigration officer] didn't even look up at me

you see! nothing changed

between July 12th and July 13th

absolutely nothing nothing changed

between July 12th and July 13th my

illegal skin my illegal bones they still

carry the same illegal me I just put my

hands up and swore an oath to the Queen

and all her mighty mighty hairs (Ziadah, "Passport" 3:53-4:27)

In other words, through the power dynamics of the collective body politic both inside and outside, the personal/individual Palestinian body is constructed as a so-called 'politicized body' that is 'stateless' and 'illegal'.

This condition of statelessness/illegality that is constantly suffered by Palestinians is more intensely experienced by Palestinian women.

the Palestine I know

the Palestine I know does not have a VIP pass

matter of fact she is stopped at every port

her skin inspected for signs of Nakbeh

and the deep scar across her body from

head to toe

she slept on the cold cement of the Cairo Airport

with her three children around her

nine months pregnant with the fourth

and with her eyes she told them

one day your Mubarak will fall for every

Palestinian that you have held in these dungeons

One Day Your Mubarak Will Fall (Rafeef Ziadah, "The Palestine I Know" 2:01-

$2: 33)$

As such, the Palestinian woman's body in Ziadah's "the Palestine I know" is one that is clearly marked by the conflation of the private and the public. Between a woman's physical experience 
of pregnancy, on the one hand, the historical experience of Nakba, and the consequent spatial curtailment of movement suffered by Palestinians at every port, on the other; the interrelationship between the personal, the historical/political, and the spatial experiences are clearly engraved on every Palestinian woman's body in "the deep scar across [a Palestinian woman's] body from head to toe" (Ziadah, "The Palestine I know" 2:13 -2:17). Despite the intensity of corporal and emotional pain inflicted on Palestinian women, Palestinian constructions of nationhood are closely aligned with notions of womanhood that defy the strictly overarching orientalist model of Arab women as "Jinnee in a bottle, belly dancer, harem girl, soft spoken Arab woman" (Ziadah, "Shades" 2:51 - 2:57). Instead, in its marked distinctiveness as a deeply scarred body, the Palestinian woman's body weaves in its indents the narrative of a whole nation, both Arab and Palestinian. Her body is the common ground that ties together Palestinian womanhood, with their systematic detainment at every port, with the fate of Palestinians in Egypt whose unjustified imprisonment in Egypt's 'dungeons' represents part of the story of Mubarak's downfall. In other words, despite the clearly visible social dynamics of Palestinian women's lives (as overly burdened with kids, three kids in this woman's case in addition to her pregnancy with the fourth), the political dynamics of their experiences can not be ignored because they are as equally inscribed on their bodies. The Palestinian woman's body, as such, carries the story of her people.

This means that beyond the bodily-engraved witnessing experienced through gestures as the performing poet 'expresses' his/her feelings on stage, Ziadah's performance poetry highlights the symbolic thematic manifestations of the Palestinian body as an experiencing medium of everyday life both inside and outside the Palestinian boundaries. Ziadah's repeated references to Mubarak's doomed downfall: "One Day Your Mubarak Will Fall" (Ziadah, "The Palestine I Know" 2:01 - 2:33) creates a sense of bond between Egyptians and Palestinians that can only manifest in bringing down dominant structures of power. In the process of drawing attention to the circles of oppression that bind Palestinians to other marginalized communities in authoritarian Arab regimes, Ziadah turns the beautifully aesthetic experience of poetry into a whole new realm through which she raises awareness of her people's cause at the same time that she mobilizes them into action. Theodor Adorno takes this point further by asserting that art expresses what knowledge fails to communicate: 'Suffering' (18). Following Hegel's conception of art, Adorno believes that if "truth is concrete, [then it] can perhaps suffice only for art" (18). Accordingly, what remains 'repressed' in the field of knowledge because of its failure to express its intensity, insanity, and brutality can only be expressed through art. Adorno states.

In its pleasure in the repressed, art at the same time takes into itself the disaster, the principle of repression, rather than merely protesting hopelessly against it. That art enunciates the disaster by identifying with it anticipates its enervation; this, not any photograph of the disaster or false happiness, defines the attitude of authentic contemporary art to a radically darkened objectivity; the sweetness of any other gives itself the lie. (19)

This idea clearly speaks to the evolving political role of performance poetry as part of a growing aesthetics of protest that include street music, graffiti, street theater, activist theater, forum theater, underground music, and street murals. These cultural practices have taken previously confined forms of artistic expressions from the precincts of concert halls, art galleries, opera houses, or even the limited space of the book (in case of poetry for example) into the vastness and openness of streets, live audience, and spontaneous hands-on feedback. But more importantly, they have managed to draw attention to real concerns, collective dreams, and common grounds of 'suffering', to use Adorno's word. 
Adorno's belief in art's ability to reflect the "pleasure in the repressed' is more broadly investigated in John Holloway's belief that "[ $[\mathrm{t}]$ hat which exists depends for its existence on that which exists only in the form of its denial ....That is the basis for hope" (36). Likewise, Ziadah believes that what represents the foundational crux of performance poetry is the "oppositional' aspect of both content and form (9:47 - 9:50). She adds:

I strive for political content and I think one crucial way to gauge social movements is the cultural production that's happening, so I think spoken word hopefully can bridge that gap between the political and the artistic and between culture and politics and I think as a form it does that beautifully. ("Rear Window" 9:53-10:15)

In "If my words" Ziadah begins her emotionally intense 'elevator pitch' marking the 2014 attack on Gaza as the reason behind her performance poem, but more importantly voicing a heart-wrenching denunciation of military aggression and heinous worldwide media coverage of Israeli mass massacres of Palestinians. Through this 'scream', to use Holloway's word, that is intensely steeped in what we may call 'the dissent of negativity,' hope is not only possible but inevitable. The scream, Holloway argues, derives "not from our humanity, but from the negation of our humanity, from the feeling that humanity is not- yet" (25). It is a scream that is saturated in 'negating the negation' of Palestinians' everyday reality (through demolitions, the separation barrier along the Green line, and their denied citizenship), before and without future televised mass slaughters. It is a scream that promotes awareness, change, and 'doing' through a heartfelt plea for "action, serious action and solidarity before the next round of thousands being massacred on TV screens" (Ziadah, "If my Words" 0:00 - 0:49). Read through Holloway's theory of revolutionary 'doing', we are screaming not simply because it is part of being human, but because we are denied that part. In other words, it is our distance from what 'is' our true nature as humans that drives us to scream 'into' humanity (25). The scream, as such, is one of 'hope' as Holloway believes. Ziadah endorses this 'hopeful' scream as she notes,

\author{
but we're holding our ground \\ we're still smiling \\ we're still smiling in Gaza \\ then we are holding our ground \\ we are holding our ground (2:00 - 2:08)
}

The same call for dissent that is ingrained in "negating the negation" of their existence is reiterated in Ziadah's "Hadeel" as she calls for people to "carry on the fight" $(2: 29-2: 31)$. This fight transcends giving people a 'recorded memory' through spoken word poetry. It is one that promotes Palestinians' basic right of return to their homeland, as a UN adopted principle of justice that lies at the forefront of the Palestinian struggle, and also as a deep-seated dream to reunite with the land and memories that have been integral to who they are. In "Shades of Anger" Ziadah maintains that Palestinian women "will cross their barriers, their check points / their damn apartheid walls and return to [their] homeland." Later, she adds:

So let me just tell you this womb inside me

will only bring you your next rebel

She will have a rock in one hand and a Palestinian flag in the other

I am an Arab woman of color

Beware! Beware my anger..."

In other words, dissent against their negated or abrogated right of return is manifested in a physical journey of return as well as the more forceful emotional/bodily journey of giving birth to more 'rebels' that carry on both physical resistance and an abiding dream for Palestinian statehood, symbolized by the rock and the Palestinian flag respectively. 
The thematic oppositional stance of Ziadah's performance poetry, however, transcends the political and historical borders of the Arab World. Ziadah's spoken word binds her struggle to other people's, specially black people's, in order to connect others with the injustice and oppression suffered by Palestinians through the 'dissent of negativity.' In "The Palestine I know," Ziadah defines Palestinian resistance through the politics of dissent of black people. She notes,

The Palestine I know does not have a VIP pass

She does not negotiate the size of our prison

She does not negotiate the size of our prison

She breaks the walls

She does not dialogue across the bar

She does not dialogue across our prison bars

She breaks those bars and beats them to the rhythm of old slave songs

Freedom

She breaks those bars and beats them to the rhythm of old slave songs

Freedom

She beats those bars, beats those bars to the rhythm of old slave songs

Freedom .... Freedom .... Freedom .... (2:58 -3:44)

In this excerpt, Ziadah relates her history to a whole history of cultural and political dissent: that of the salve songs. Slave songs were the African slaves' lyric poems that acted as a means for social communication, self-expression and political dissent (Ramey 112). Like old slave songs that 'expressed' and documented the daily hardships of slavery and the robust quest for freedom, Ziadah stresses this point further. She uses full words with "she does not" rather than contractions (doesn't) in order to emphasize the negation of any form of 'negotiation or 'dialogue' over the terms of their imprisonment, military occupation, mass incarceration, or 'modern slavery.' The same practice is followed in "Shades of Anger" where Ziadah repeats "I am an Arab woman of color and we come in all shades of anger" six times throughout the poem to stress more than an unwavering sense of dissent. Rather, Ziadah's repetition of the word "color" taps into a long existing past of indignation, incarceration, and pain that connects people across cultures through the prism of color.

Jacques Rancièr maintains that through this resistive attitude to power "[ $\mathrm{t}]$ he politics of dissent ... render new actors, struggles and ways of organization visible" (qtd. in Jørgensen and Agustín 12-13). In other words, not only do these examples express the emotional intensity of Palestinian experiences, but they also help to solicit support for their cause, reexamine their legacy of resistance, at the same time that they resituate this same legacy within a global context by comparing it to others' history(ies).

According to John Holloway, these "relations of comradeship, of solidarity, of love, relations ... prefigure the sort of society we are struggling for" and cultivate "human potential (to emancipate power-to) is always a struggle- against...." Holloway perceives this 'struggleagainst' in the ability to see beyond the current state of affairs or the 'indicative' into what is "yet-to-be' or the 'subjunctive' that carries within it the future possibility $(7,153)$. In the same way that gestures carry a social value in its interactional capacity with the audience, the spoken word is a social act that should be perceived as one of holding onto 'the dissent of negativity' as a challenging power that can propel us forward into an indeterminate future and a presumed, yet healthy, chaos. However, it is the only way that can generate new meanings and possible alternatives toward freedom. Holloway asserts, 
'We are not' becomes, therefore, 'We are not yet', but only if 'not- yet' is understood not as certain future, secure homecoming, but as possibility, as a becoming with no guarantees, no security. If we are not yet, then our not-yet-ness already exists as project, as overflow- ing, as pushing beyond ... Human existence is not just an existence of negation but an existence of not-yet-ness, in which negation, by being negation of the negation of our humanity, is at the same time a projection towards that humanity. Not a lost humanity, nor an existing humanity, but a humanity to be created. This not-yetness can be seen not just in overt political militancy, but in the struggles of everyday living, in the dreams we have, in our projections against the denial of our projections, in our fantasies, from the simplest

dreams of pleasure to the most path-breaking artistic creations ... Not-yet-ness is a constant drive against an is-ified reality, the revolt of the repressed Pleasure Principle against the Reality Principle. Not-yet-ness is the struggle to de-congest time, to emancipate power-to (152-3)

Beyond the constricted realm of traditional poetry, performance poetry takes us into the expansiveness of gestural, visual and verbal experience that serve to enhance the aesthetic interpretation and meaning of the performed poem. In other words, the shift from the textual medium of written poetry into the audiovisual medium of performance poetry has managed to render a 'live' materialized hands-on 'visibilty' that have been unattended through traditional means. The performing body of the poet is one that engages with the illegality and political legacies of a long history of oppression and dispossession. In the interaction between the physical performing body's movement and gestures and the imagined body, through the reenactment of the physical experience as memory of pain and resistance, dispossession and defiance or negation and dissonance; the performing poem becomes a site of conflation and engagement between reality and imagination, body and feelings, past and present, art and politics. Between the aesthetic body manifested in the performative tools of gestures and dress, and the collective body memory manifested in the semantic and contextual experiences of the body, Ziadah has established a new aesthetic imaginary that transforms into innovative and subversive capacities for social and political transformation through the empowering medium of words. Through these tools, Ziadah has managed to create an alternative mentally and politically charged space where movement, dress, language and instrumentalism are integral parts of the aesthetic experience through which performance poetry can communicate the rich complexity of the Palestinian experience.

\section{Notes}

${ }^{1}$ Elsawy Culture Wheel is a private local cultural center that is known for providing a free venue for artistic and cultural expression for both professional and amateur artists in Egypt

${ }^{2}$ For example America's Got Talent or Britain's Got Talent, or American Idol.

3 A famous and well-acclaimed TV competition show that was produced by Aby Dhabi Television network in 2007

${ }^{4}$ Poetrysoup is an online international poetry circuit through which talented poets would come together to post short poems of about 500 words and to participate in online poetry contests.

${ }^{5}$ It is the act of hand twirling into what David Givens calls a "slap-down position" (46).

${ }^{6}$ Inter-sential Code switching refers to the language alternations that occurs after a sentence and between two languages.

\section{Works Cited}

Adorno, T.W. Aesthetic Theory, edited by Gretel Adorno and Rolf Tiedemann, translated by Robert Hullot-Kentor. University of Minnesota Press, 1997. 
Attridge, Derek. The Experience of Poetry: From Homer's Listeners to Shakespeare's Readers. Oxford University Press, 2019.

Adonis, and Catherine Cobham. An Introduction to Arab Poetics. Saqi Books, 2003. Internet Archive, archive.org/stream/MyStuff129/An\%20Introduction\%20to\%20Arab\%20Poetics\%20b y\%20Adonis_djvu.txt

Barrows-Friedman, Nora. "Listen: Rafeef Ziadah On Why "it's difficult to separate politics from poetry"' The Electronic Intifada, 23 Dec 2015, electronicintifada.net/blogs/norabarrows-friedman/listen-rafeef-ziadah-why-its-difficult-separate-politics-poetry.

Broome, Jeffrey L., and Lisa Munson. Hip-hop, Art, and Visual Culture: Connections, Influences, and Critical Discussions. MDPI AG, 2020.

Collingwood, R. G. The Principles Of Art. Oxford University Press, 1938. Internet Archive, archive.org/details/in.ernet.dli.2015.188470/page/n5/mode/2up. Accessed 12 Apr. 2020.

Constantine, David. Poetry: The Literary Agenda. Oxford University Press, 2013. Google Books,

books.google.com.eg/books?id=_ZH4AAAAQBAJ\&pg=PT10\&dq=\%22words\%22+ $\% 22$ poetry $\% 22 \& h l=e n \& s a=X \& v e d=0 a h U K E w j l j u T z 5 O j o A h V j x Y U K H d v X C y w 4 M$

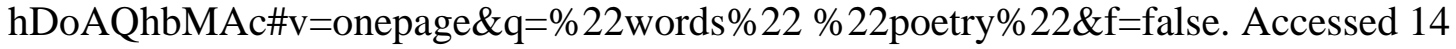
Apr. 2020.

Diffey, Terry. Tolstoy's 'what Is Art?' Routledge, 2014.

"Explore Iraq's Ninth-Century Literary Salons." ArabLit Quarterly, 12 Dec. 2020, arablit.org/2010/11/20/an-exploration-of-iraqs-ninth-century-literary-salons.

Felix-Jager, Steven. Pentecostal Aesthetics: Theological Reflections in a Pentecostal Philosophy of Art and Aesthetics. Brill, 2015. Google Books, books.google.com.eg/books?id=lftyBgAAQBAJ\&pg=PA75\&lpg=PA75\&dq=Penteco stal+Aesthetics:+Theological+Reflections+in+a+Pentecostal+Philosophy+of+Art+an $\mathrm{d}+$ Aesthetics\&source=bl\&ots=GvnBKGKBn_\&sig=ACfU3U06-

07GyfHt5hIKgtFR130oWDkh2A\&hl=en\&sa=X\&ved=2ahUKEwjV0ruom_DpAhUPz oUKHcmpClc4ChDoATAAegQICRAC\#v=onepage \&q=emancipating \&f=false. Accessed 14 Apr. 2020.

Galhano-Rogues, Isabel, Elena Z. Galvô, and Anabela Cruz-Santos. Recent Perspectives on Gesture and Multimodality. Cambridge Scholars Publishing, 2019. Google Books, www.books.google.com.eg/books?id=fn6jDwAAQBAJ\&pg=PA104\&lpg=PA104\&d $\mathrm{q}=$ pointing+downward+rap+gesture \&source=bl\&ots=qoyqgE8rc0\&sig=ACfU3U1rn _eayRZ1wDCcxlmffb4o-

VGODg\&hl=en\&sa $=X \& v e d=2$ ahUKEwjYqOu6gdXpAhWqxoUKHWcsCWYQ6AE wDHoECBAQAQ\#v=onepage $\& \mathrm{q}=$ cambridge $\% 20 \& \mathrm{f}=$ false

Givens, David B. Your Body at Work: A Guide to Sight-Reading the Body Language of Business, Bosses, and Boardrooms. Griffin, 2010. 
Grabner, Cornelia. "Performance Poetry: New Languages and New Literary Circuits?" World Literature Today, vol. 82, no. 1, January- February 2008, pp. 1- 4. www.academia.edu/423554/The_Poetics_of_Performance_Poetry

Guter, Eran. Aesthetics A-Z. Edinburgh University Press, 2010. JSTOR, www.jstor.org/stable/10.3366/j.ctt1g0b1jt. Accessed 4 May 2020.

Halliwell, Stephen. The Aesthetics of Mimesis: Ancient Texts and Modern Problems. Princeton UP, 2002.

Holloway, John. Change the World Without Taking Power. Pluto Press, 2002.

Jay, Jacqueline E. Orality and Literacy in the Demotic Tales. Brill, 2016.

Jørgensen, M.B., and O.G. Agustin. "The Politics of Dissent." Politics of Dissent, edited by M. B. Jørgensen, \& Ó. G. Agustín. Political and Social Change, vol. 1, 2015, pp. 11-25.

Lee, Carmen. Multilingualism Online. Routledge, 2016.

Lindroos, Kia, and Frank Möller. Art As a Political Witness. Verlag Barbara Budrich, 2017.

Lutterbie, John. "Transforming Gesture to Sign in the Theatre." Pucsp. www4.pucsp.br/pos/tidd/teccogs/artigos/2010/edicao_4/3-

transforming_gesture_to_sign_in_the_theatre-john_lutterbie.pdf. Accessed 15 May 2020.

McNeill, David. Why We Gesture: The Surprising Role of Hand Movements in Communication. Cambridge University Press, 2016.

Mejcher-Atassi, Sonja. Archives, Museums and Collecting Practices in the Modern Arab World. Routledge, 2016.

Michel, Alexandra. "Cognition and Perception: Is There Really a Distinction?" Psychological Science, 29 Jan. 2020, www.psychologicalscience.org/observer/cognition-andperception-is-there-really-a-distinction.

Mooney, Kempton. The Evolution of Conceptual Art in America. FKM Books, 2000.

Parzuchowski, Michal, et al. "From the Heart: Hand over Heart as an Embodiment of Honesty." Cognitive Processing, vol. 15, no. 3, Springer Verlag, 2014, pp. 237-44, doi:10.1007/s10339-014-0606-4.

Ramey, Lauri. Slave Songs and the Birth of African American Poetry. Palgrave Macmillan, 2008.

"Rear Window - Rafeef Ziadah Power of the Spoken Word." YouTube, uploaded by The World Today with Tariq Ali, 30 Sep. 2015, www.youtube.com/watch?v=pwk5LjL6bE.

Richter, David. The Critical Tradition : Classic Texts and Contemporary Trends. St. Martin's Press, 1989, www.worldcat.org/title/critical-tradition-classic-texts-and-contemporarytrends/oclc/20377367\&amp;referer=brief_results\#.XpclPbvMGlw.mendeley.

Rizzolatti, G, and L Craighero. "The Mirror-Neuron System." Annual Review of Neuroscience, vol. 27, July 2004, pp. 169-92. Print.

Smith, Ralph A. The Sense of Art: A Study in Aesthetic Education. Routledge, 2014. 
Ziadah, Rafeef. ---. "Hadeel." YouTube, uploaded by Studio Revolt, 23 Nov. 2012, www.youtube.com/watch?v=qyra1CWvw-U

---. "Shades of Anger." YouTube, uploaded by sternchenproductions, 16 Nov. 2016, www.youtube.com/watch?v=m2vFJE93LTI

---. "We teach life, sir." YouTube, uploaded by sternchenproductions, 13 Nov. 2011, www.youtube.com/watch?v=aKucPh9xHtM.

---. "Passport." YouTube, uploaded by Rafeef Ziadah, 8 Nov. 2016, www.youtube.com/watch?v=-opH7XOMbSY

---. "The Palestine I Know." YouTube, uploaded by Rafeef Ziadah, 20 Oct. 2016, www.youtube.com/watch?v=xkDCRIStICE.

---. "If My Words." YouTube, uploaded by Rafeef Ziadah, 20 Oct. 2016, www.youtube.com/watch?v=thVPpbpqVbo

Zwettler, Michael. The Oral Tradition of Classical Arabic Poetry: Its Character and Implications. Ohio State University Press, 1978. 